\title{
Update on the diagnosis and management of acute kidney injury
}

\author{
This article was published in the following Dove Press journal: \\ International Journal of Nephrology and Renovascular Disease \\ 28 September 2010 \\ Number of times this article has been viewed
}

\author{
Ali Akcay \\ Kultigin Turkmen \\ DongWon Lee \\ Charles L Edelstein \\ Division of Renal Diseases and \\ Hypertension, University of Colorado \\ and the Health Sciences Center, \\ Aurora, Colorado, USA
}

\begin{abstract}
Acute kidney injury (AKI) is an independent risk factor for morbidity and mortality. This review provides essential information for the diagnosis and management of AKI. Blood urea nitrogen and serum creatinine are used for the diagnosis of AKI. The review also focuses on recent studies on the diagnosis of AKI using the RIFLE (R-renal risk, I-injury, F-failure, L-loss of kidney function, E-end stage kidney disease) and Acute Kidney Injury Network criteria, and serum and urine AKI biomarkers. Dialysis is the only Food and Drug Administration-approved therapy for AKI. Recent studies on the dose of dialysis in AKI are reviewed.
\end{abstract}

Keywords: acute kidney injury, biomarkers, interleukin-18

\section{Diagnosis of acute kidney injury}

Acute kidney injury (AKI) is characterized by a sudden impairment of kidney function occurring over a period of hours to days. A diagnosis of AKI is currently made on the basis of the presence of increased serum creatinine and/or blood urea nitrogen (BUN) levels and/or a decreased urine output, despite their well-known limitations. It should be noted that changes in BUN and serum creatinine may represent not only renal injury, but also normal responses of the kidney to extracellular volume depletion or decreased renal blood flow.

Recent developments in the diagnosis of AKI include 1) use of the RIFLE (R-renal risk, I-injury, F-failure, L-loss of kidney function, E-end stage kidney disease [ESKD]) and AKIN (Acute Kidney Injury Network) criteria and 2) use of biomarkers of AKI.

\section{RIFLE or AKIN criteria (Table I)}

Small increases of serum creatinine levels in hospitalized patients are associated with substantial morbidity and mortality. ${ }^{1}$ The Acute Dialysis Quality Initiative developed a consensus definition and classification of AKI based on creatinine increase and decrease in glomerular filtration rate (GFR) or urine output: the RIFLE criteria. More recently, the RIFLE criteria were modified by the AKIN. The criteria are identical to the first three stages of RIFLE, with the exception of a shorter time frame of AKI within 48 hours, and a lower creatinine threshold of greater than $0.3 \mathrm{mg} / \mathrm{dL}$ from baseline to peak value (Table 1). The prognostic values of the RIFLE and AKIN criteria have been validated for in-hospital mortality in numerous studies including cardiothoracic surgery, trauma, or critically ill patients and they provide a uniform definition of AKI. ${ }^{1-4}$ A new study comparing the diagnostic and prognostic factors of the RIFLE and AKIN classifications for AKI after cardiac surgery showed that both are equally useful in diagnosis and accurate in prognosis..$^{5}$
Correspondence: Charles L Edelstein Division of Renal Diseases and Hypertension, University of Colorado and the Health Sciences Center, Box C28I, 12700 East 19th Ave, Aurora, CO 80262, USA

$\mathrm{Tel}+\mathrm{I} 3037244810$

Fax + I 3034868

Email charles.edelstein@ucdenver.edu submit your manuscript $\mid$ www.dovepress.com

Dovepress

DOI: $|0.2147 /| J N R D . S 864 \mid$ 
Table I RIFLE and AKIN criteria for diagnosis of AKI

\begin{tabular}{lll}
\hline RIFLE criteria (within $\mathbf{7}$ days) & & Urine output criteria \\
\hline Class & GFR criteria & $0.5<\mathrm{mL} / \mathrm{kg} / \mathrm{hour} \times>6 \mathrm{hours}$ \\
\hline R-Risk & Creatinine increase $\times 1.5$ or GFR loss $>25 \%$ & $0.5<\mathrm{mL} / \mathrm{kg} / \mathrm{hour} \times>12 \mathrm{hours}$ \\
I-Injury & Creatinine increase $\times 2$ or GFR loss $>50 \%$ & $0.3<\mathrm{mL} / \mathrm{kg} / \mathrm{hour} \times>24 \mathrm{hours}$ \\
F-Failure & Creatinine increase $\times 3$ or GFR loss $>75 \%$ or & or anuria $>12 \mathrm{hours}$ \\
& creatinine increase $>4 \mathrm{mg} / \mathrm{dL}$ (acute increase $>0.5 \mathrm{mg} / \mathrm{dL}$ ) & \\
L-Loss & Persistent loss of kidney function $>4$ weeks & Urine output criteria \\
E-ESKD & ESKD $>3$ months & $0.5<\mathrm{mL} / \mathrm{kg} / \mathrm{hour} \times>6 \mathrm{hours}$ \\
\hline AKIN criteria (within $\mathbf{4 8}$ hours) & $0.5<\mathrm{mL} / \mathrm{kg} / \mathrm{hour} \times>12 \mathrm{hours}$ \\
\hline Stage & Serum creatinine criteria & $0.3<\mathrm{mL} / \mathrm{kg} / \mathrm{hour} \times>24 \mathrm{hours}$ \\
\hline I & Creatinine increase $\times 1.5$ or creatinine increase $>0.3 \mathrm{mg} / \mathrm{dL}$ & or anuria $>12$ hours \\
\hline 3 & Creatinine increase $\times 2$ & \\
\hline
\end{tabular}

\section{Biomarkers of $\mathrm{AKI}$}

Serum creatinine is the most widely used parameter to assess renal function. Unfortunately, serum creatinine is not a very reliable marker of AKI in many patients. There are many renal and non-renal factors that influence serum creatinine independent of kidney function. For example, creatinine generation is proportional to muscle mass and is affected by age, gender, body weight, and diet. ${ }^{6-8}$ The most important limitation of serum creatinine is the delayed increase of serum creatinine levels after actual changes in GFR. In addition, serum creatinine levels may vary with intravascular volume expansion or depletion and with hemodynamic changes, regardless of renal function. These problems often lead to delayed recognition of AKI and late initiation of treatment in especially intensive care unit (ICU) patients and elderly. ${ }^{9}$

Many biomarkers have been widely studied for use in the diagnosis of AKI because serum creatinine is an imperfect marker for the early and accurate diagnosis of AKI. A biomarker that is released into the blood or urine from the injured kidney soon after AKI may be an earlier marker of AKI than serum creatinine. Early diagnosis of AKI may result in more optimal dosing of antibiotics, avoidance of nephrotoxic agents, and earlier nephrology consultation. The most promising early biomarkers of AKI are interleukin-18 (IL-18), neutrophil gelatinase-associated lipocalin (NGAL), kidney injury molecule-1 (KIM-1), and cystatin $\mathrm{C}$.

In addition to being a mediator of AKI, IL-18 is also a biomarker of AKI. IL-18 is increased in the urine in mice with AKI. ${ }^{10,11}$ Urine IL-18 is increased in patients with AKI compared to other kidney diseases and in renal transplant patients with delayed graft function. ${ }^{12,13}$ Urine IL-18 increases
48 hours before a $50 \%$ increase in serum creatinine in critically ill adults with acute respiratory distress syndrome, ${ }^{14}$ children with AKI in the ICU, ${ }^{15}$ children that develop AKI post cardiopulmonary bypass ${ }^{16}$ and in adults with contrast nephropathy. ${ }^{17}$

NGAL is a small protein of the lipocalin superfamily and is expressed by renal tubular cells. ${ }^{18}$ NGAL protein increases in the kidney, in the urine in early ischemic AKI in rats and mice, ${ }^{19}$ and in the early stage of cisplatin-induced AKI. ${ }^{20}$ NGAL increases in the urine before serum creatinine in children and adults with AKI post cardiopulmonary bypass, ${ }^{21,22}$ children with AKI in the ICU, ${ }^{23,24}$ and adults and children with contrast nephropathy. ${ }^{25,26}$ Urine and plasma NGAL predicts AKI in critically ill adults. ${ }^{27,28}$ Plasma NGAL concentrations obtained during surgery are highly associated with postoperative AKI in patients undergoing liver transplantation. ${ }^{29}$ A more recent meta-analysis of 12 adults and seven children studies including cardiac surgery, contrast nephropathy, and critically ill patients demonstrated that plasma and urine NGAL levels appear to be of diagnostic and prognostic value for AKI. ${ }^{30}$

KIM-1 is an epithelial cell adhesion molecule that is expressed at a low level in normal kidney. KIM-1 is increased in the kidney in ischemic AKI in rats and mice. ${ }^{31,32}$ Urinary KIM-1 is increased in patients with acute tubular necrosis (ATN), ${ }^{33}$ and is a predictor of graft loss in kidney transplant patients. ${ }^{34}$ More recently, a rapid KIM-1 urine dipstick was developed for the early detection of kidney injury. ${ }^{35}$ In another study, it has been shown that a panel of urinary biomarkers including NGAL, N-acetyl- $\beta$-(D)glucosaminidase and KIM-1 may improve the early detection of postoperative AKI after cardiac surgery before a rise in serum creatinine. ${ }^{36}$ 
Cystatin $\mathrm{C}$ is a protein produced by all nucleated cells compared to creatinine that is produced by muscle. It is freely filtered by the glomerulus. ${ }^{37}$ Cystatin $\mathrm{C}$ is an earlier marker of AKI than serum creatinine in patients with $\mathrm{AKI}$ and adults post cardiopulmonary bypass. ${ }^{38,39}$ Serum cystatin $\mathrm{C}$ is a more accurate marker of GFR than serum creatinine in contrast nephropathy, ${ }^{40}$ liver cirrhosis, ${ }^{41,42}$ and critically ill adults and children. ${ }^{43,44} \mathrm{~A}$ more recent study showed that serum cystatin $\mathrm{C}$ level performs similarly to serum creatinine level, serum urea nitrogen level, and urine output for predicting dialysis requirement or in-hospital death in patients with $\mathrm{AKI} .{ }^{45}$

Other biomarkers of AKI are fatty acid-binding proteins, netrin-1, tubular enzymes, IL-6 and IL-8.

\section{Diagnosis of the cause of AKI}

The causes of AKI may be prerenal (Table 2), post renal (Table 3), or intrinsic renal (Table 4). An approach to determining the cause of AKI includes a careful history, physical examination, and examination of the urine.

\section{History and physical examination}

A careful recording of patient data (vital signs, daily weights, records of intake and output, past and current laboratory

Table 2 Conditions causing prerenal azotemia

\begin{tabular}{l} 
Hypovolemia \\
Hemorrhage \\
Gastrointestinal losses \\
Third space \\
Burns \\
Peritonitis \\
Muscle trauma \\
Renal fluid losses \\
Overdiuresis \\
Impaired cardiac function \\
Congestive heart failure \\
Cardiogenic shock \\
Acute myocardial infarction \\
Pericardial tamponade \\
Massive pulmonary embolism \\
Systemic vasodilatation \\
Gram-negative bacteremia \\
Antihypertensive medications \\
Anaphylaxis \\
Cirrhosis \\
Increased renal vascular resistance \\
Anesthesia \\
Surgery \\
Hepatorenal syndrome \\
Prostaglandin inhibitors \\
NSAIDs \\
Renal vasoconstricting drugs \\
Cyclosporin \\
\hline
\end{tabular}

Table 3 Conditions causing postrenal azotemia

Urethral obstruction
Valves
Stricture
Bladder neck obstruction
Prostatic hypertrophy
Bladder carcinoma
Bladder infection
Functional
Autonomic neuropathy
Alpha adrenergic blockers
Bilateral obstruction of ureters (unilateral obstruction in
solitary kidney)
Intraureteral
Sulphonamide, uric acid, acyclovir, anti-retroviral agent crystals
Blood clots
Stones
Necrotizing papillitis
Extraureteral
Tumor of cervix, prostate, bladder
Endometriosis
Periureteral fibrosis
Accidental ureteral ligation
Pelvic abscess or hematoma

data, fluid balance, and medication) should be documented. Careful analysis of the history to detect causes of AKI like administration of non-steroidal anti-inflammatory drugs (NSAIDs), diuretics, radiocontrast agents, or antibiotics should be performed.

A careful evaluation by the history and physical examination for causes of prerenal, postrenal, or intrarenal azotemia is the most important classical approach to the early diagnosis of the cause of AKI.

\section{Prerenal azotemia}

The conditions causing prerenal azotemia are listed in Table 2. There are four criteria required for a diagnosis of prerenal azotemia: 1) an acute rise in BUN and/or serum creatinine, 2) a cause of renal hypoperfusion, 3) a bland urine sediment (absence of cells and cellular casts) or fractional excretion of sodium $\left(\mathrm{FE}_{\mathrm{Na}}\right)$ of less than $1 \%$, and 4$)$ the return of renal function to normal within 24-48 hours of correction of the hypoperfused state.

\section{Postrenal azotemia}

Obstruction of urine flow in both ureters, the bladder, or urethra or obstruction of a solitary kidney may cause postrenal AKI. The common causes of postrenal AKI are listed in Table 3. The common denominator of acute azotemia in this setting is obstruction to the flow of urine. The patient most at risk for acute postrenal azotemia is the elderly man in whom prostatic hypertrophy or prostatic cancer may lead 
Table 4 Conditions that cause parenchymal (intrinsic) AKI

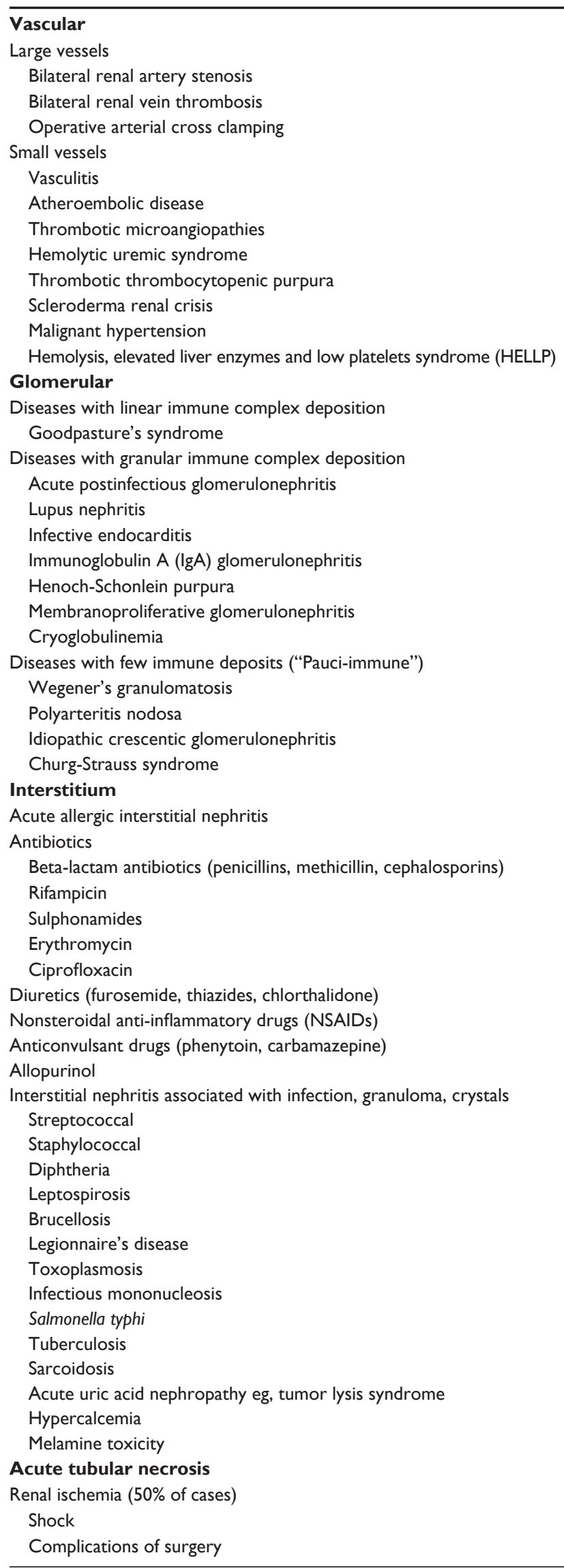

(Continued)
Table 4 (Continued)

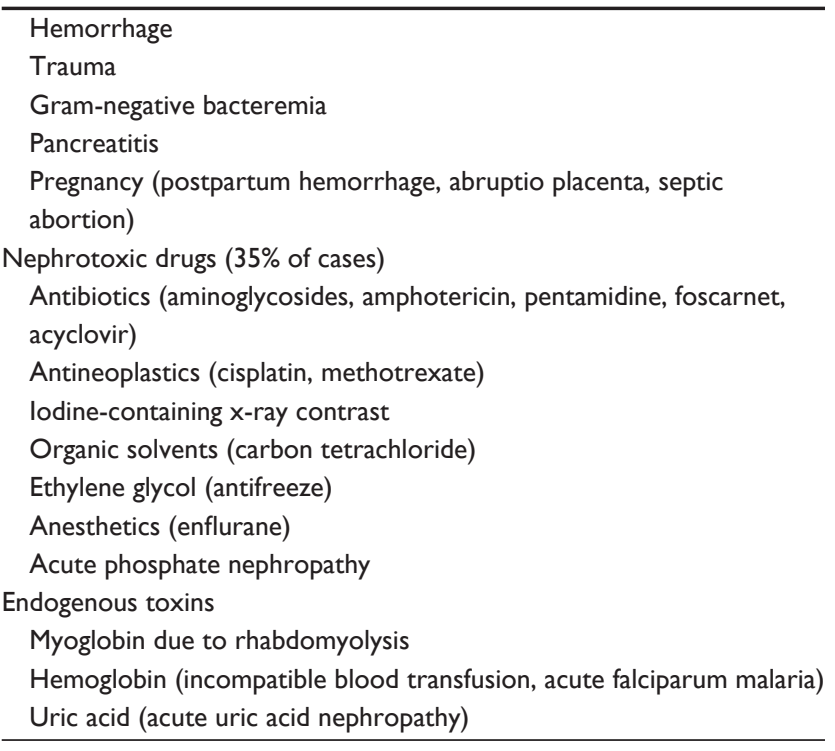

to complete or partial obstruction to urine flow. A pelvic examination is mandatory in the evaluation of postrenal azotemia, because patients with cervical or endometrial carcinoma or endometriosis may present with azotemia secondary to bilateral ureteral obstruction. Renal ultrasonography will detect pelvicalyceal dilatation secondary to obstruction in more than $90 \%$ of patients.

\section{Intrinsic (intrarenal) AKI}

After prerenal and postrenal azotemias have been excluded, the diagnosis of intrarenal AKI can be considered (Table 4).

\section{Urinalysis Microscopy}

Assessment of the urinary sediment also is crucial in the diagnosis of AKI. An active sediment with renal tubular epithelial cells, cellular debris, and "muddy brown" broad tubular cell casts supports the diagnosis of ATN. Large amounts of urinary protein $(>3.0 \mathrm{~g} / 24$ hours $)$ and numerous red blood cell casts are indicative of AKI secondary to acute glomerulonephritis or vasculitis. The absence of cellular elements and protein in the urine is most compatible with prerenal and postrenal azotemia. An abundance of crystals in the urine such as uric acid or oxalate crystals secondary to ethylene glycol or methoxyflurane toxicity or crystalluria in an AIDS patient being treated with acyclovir or indinavir also may provide a clue to the specific cause of the AKI. A recent study reviewed the literature from 1960-2009 for studies on urine microscopy with sediment examination for the differential diagnosis or risk stratification of AKI. ${ }^{46}$ The study concluded that urine microscopy with sediment examination has merit for differentiating ATN from prerenal 
AKI. Similarly, they found that the presence and number of renal tubular epithelial cells and renal tubular epithelial cell casts and/or granular casts in the urine sediment may help in the diagnosis of ATN and may be useful in predicting more severe kidney damage (non-recovery of AKI and need for dialysis). ${ }^{46}$ In a subsequent study, a scoring system based on the number of renal tubular epithelial cells and granular casts in the urine was developed to evaluate the severity and worsening of $\mathrm{AKI} .{ }^{47} \mathrm{~A}$ urine sediment score of greater than or equal to three versus zero on an ATN urinary sediment scoring system was a significant predictor of worsening of AKI (progressing to a higher AKIN stage [Table 1], dialysis, or death) (Table 5). ${ }^{47}$

\section{Urine biochemistry}

Considerable information may be obtained from the assessment of the urinary composition. ${ }^{48,49}$ A classical study by Miller and associates ${ }^{48}$ evaluated the differences in urinary composition between prerenal azotemia and both oliguric and nonoliguric AKI. Those differences are summarized in Table 6. If mannitol or a diuretic has been administered within a few hours of obtaining the urine for examination, the interpretation of the urinary composition is difficult because with prerenal azotemia the administration of either of these substances may raise the urinary sodium concentration and impairs renal concentrating capacity. $\mathrm{FE}_{\mathrm{Na}}$ is increased in ATN, but may be low in association with AKI caused by nonoliguric ATN, radiocontrast, hepatorenal syndrome, rhabdomyolysis, acute glomerulonephritis, vasculitis, and early obstructive uropathy. ${ }^{50}$

\section{Clinical features of common causes of AKI \\ Sepsis}

Sepsis is the most frequent cause of $\mathrm{AKI}$ in intensive care units. ${ }^{51,52}$ AKI occurs in approximately $19 \%$ of patients with moderate sepsis, $23 \%$ of patients with severe sepsis, and $51 \%$ of patients with septic shock. ${ }^{53}$ The combination of AKI and sepsis is associated with more than $80 \%$ mortality. ${ }^{52}$

\section{Nephrotoxins}

Nephrotoxins are an important cause of AKI. Some important nephrotoxins are aminoglycoside antibiotics, radiocontrast media, NSAIDs, cisplatin, and amphotericin B.

The aminoglycosides are major antibiotics in the treatment of serious gram-negative infections. Their increased use and potential nephrotoxic risk have made them a frequent cause of AKI. AKI occurs in 10-25\% of patients on aminoglcosides even with careful dosing and therapeutic plasma levels. Aminoglycoside-induced nephrotoxicity is characterized by slow rises in serum creatinine, tubular necrosis, and marked decreases in GFR and in the ultrafiltration coefficient.

Several factors may predispose to aminoglycoside nephrotoxicity. These include advancing age, underlying renal disease, volume depletion, hypertension, and recent exposure to aminoglycosides or other nephrotoxic drugs. The clinical course of aminoglycoside nephrotoxicity is usually gradual in onset and is related to the dose and duration of drug exposure. Frequently, mild proteinuria, lysozymuria, a defect in concentrating ability, and polyuria precede a decline in glomerular filtration. Early findings are isothenuria secondary to nephrogenic diabetes insipidus and magnesium and potassium wasting. Later findings include azotemia.

Cisplatin is a very effective chemotherapeutic agent used in a number of malignant tumors. Despite routine use of hydration and mannitol, there is still a significant incidence of renal failure. Cisplatin nephrotoxicity is cumulative and dose dependent. ${ }^{54} \mathrm{~A}$ significant and transient increase in BUN and serum creatinine is observed in most patients after a single dose of $40-100 \mathrm{mg} / \mathrm{m}^{2}$. At a high dose of $100 \mathrm{mg} / \mathrm{m}^{2}$ given over one week, there is a prolonged renal failure that can last up to two years. ${ }^{55}$

Radiocontrast-induced nephropathy (CIN) has been recognized to be a cause of AKI with increasing frequency in the past few years. The incidence of CIN is about $11.3 \%$ using the definition of a $25 \%$ increase in serum creatinine or an absolute increase in serum creatinine of $0.5 \mathrm{mg} / \mathrm{dL} .{ }^{56}$ Radiocontrast agents cause AKI by inducing renal vasoconstriction followed by hypoxic tubular injury. ${ }^{57,58}$ Predisposing factors include age

Table 5 Scoring system of AKI severity based on number of granular casts and RTE cells in urinary sediment

\begin{tabular}{llll}
\hline RTE cells (per HPF) & Granular casts (per LPF) & & $\geq 6$ (2 Points) \\
\cline { 2 - 4 } & $\mathbf{0}$ (0 Points) & I to 5 (I Point) & 2 \\
\hline 0 (0 points) & 0 & 1 & 3 \\
I to 5 (I point) & 1 & 2 & 4 \\
$\geq 6$ (2 points) & 2 & 3 & 4 \\
\hline
\end{tabular}

Notes: Values denote total points awarded. A urine sediment score of greater than or equal to three versus zero was a significant predictor of worsening of AKI (progressing to a higher AKIN stage [Table I], dialysis, or death). ${ }^{47}$ Reproduced from Perazella et al. ${ }^{47}$

Abbreviations: HPF, high-powered field; LPF, low-powered field; RTE, renal tubular epithelial. 
Table 6 Urine findings in prerenal azotemia and intrinsic AKI

\begin{tabular}{|c|c|c|}
\hline Laboratory test & Prerenal azotemia & ATN \\
\hline Urine sodium $\left(\mathrm{U}_{\mathrm{Na}}\right), \mathrm{mEq} / \mathrm{L}$ & $<20$ & $>40$ \\
\hline Urine osmolality, $\mathrm{mOsm} / \mathrm{kg} \mathrm{H}_{2} \mathrm{O}$ & $>500$ & $<400$ \\
\hline Urine to plasma urea nitrogen & $>8$ & $<3$ \\
\hline Urine to plasma creatinine & $>40$ & $<20$ \\
\hline Fractional excretion of filtered sodium & $<1$ & $>1$ \\
\hline Urinary sediment & Bland & $\begin{array}{l}\text { “Muddy” brown granular } \\
\text { casts, cellular debris, tubular } \\
\text { epithelial cells }\end{array}$ \\
\hline
\end{tabular}

( $>55$ years), prior renal insufficiency, diabetes mellitus with neurovascular complications, proteinuria, volume depletion, acute liver failure, and recent nephrotoxic drug exposure. ${ }^{59}$ The onset of renal failure usually is abrupt within 24 hours after exposure to contrast media and is characterized by oliguria, but it may be nonoliguric. ${ }^{60}$ Recovery of renal function generally occurs. However, patients with advanced renal failure, particularly diabetic patients with nephropathy, may not recover function following contrast-induced AKI and may require chronic hemodialysis therapy.

Two recent meta-analyses demonstrated that intravenous sodium bicarbonate is better than sodium chloride in preventing $\mathrm{CIN}$ as defined by an increase in serum creatinine of $25 \%$ or an absolute increase in serum creatinine of $0.5 \mathrm{mg} / \mathrm{dL}$. Intravenous sodium chloride was not different to intravenous sodium bicarbonate in preventing the need for renal replacement therapy (RRT) or death. ${ }^{56}$ Prophylactic oral administration of the antioxidant acetylcysteine, along with hydration, attenuates the reduction in renal function (defined by an increase in serum creatinine of at least $0.5 \mathrm{mg} / \mathrm{dL}$ ) induced by contrast agents in patients with chronic renal insufficiency. ${ }^{61}$

NSAIDs which are used in the management of pain and rheumatic disorders are increasingly recognized as etiologic factors in AKI. These substances, which include a large group of newer non-steroidal agents, COX-2 inhibitors, as well as aspirin and its derivatives, have in common the inhibition of prostaglandin synthesis. ${ }^{61}$ NSAID-induced AKI is due to the diminished renal vasodilatory effect of prostaglandins. Predisposing factors to NSAID-induced ischemic renal dysfunction include diuretic use, elderly age, atherosclerotic cardiovascular disease, renovascular disease, diabetes, and acute gouty arthritis. ${ }^{62}$ Patients with chronic renal insufficiency are also at risk of acute vasomotor decline in renal function with NSAIDs. Typical clinical features include the presence of risk factors, modest salt and water retention, decreased urinary output, a benign urine sediment, low $\mathrm{FE}_{\mathrm{Na}}$ (less than 1\%), and prompt improvement in renal function upon discontinuation of NSAIDs. ${ }^{63,64}$
Several of the NSAIDs have been associated with an acute allergic interstitial nephritis that is highlighted by renal failure, heavy proteinuria, and interstitial nephritis with foot process fusion (minimal change) on renal biopsy. This renal failure with NSAIDs is also generally reversible, but in a slower fashion. Most drug-related reports of acute interstitial nephritis (AIN) have been with the use of penicillin and, in particular, its synthetic analogs such as methicillin. The antibiotic-induced acute allergic interstitial nephritis may have the clinical findings of a hypersensitivity reaction with fever, rash, joint pain, and eosinophilia. The urinary sediment is not diagnostic showing mild proteinuria ( $<1.5 \mathrm{~g} / 24$ hours), pyuria, hematuria, and granular casts. Urine cultures are usually negative. In general, recovery occurs with treatment of the underlying disease or removal of the offending drug. However, there have been reports of permanent impairment of renal function or death. ${ }^{65}$ The use of steroid therapy is controversial since there is no large randomized prospective controlled study indicating a beneficial effect of steroids. ${ }^{66}$ However, a brief course of corticosteroids can hasten the recovery of renal function. ${ }^{66}$ Despite the lack of scientific evidence, a short course of prednisone in a patient whose renal function fails to improve within one week of stopping the inciting drug is recommended provided the diagnosis of AIN is confirmed by renal biopsy. ${ }^{66}$

Angiotensin converting enzyme (ACE) inhibitors and angiotensin II receptor blockers (ARBs) are widely used for the treatment of hypertension, chronic kidney disease, and congestive heart failure. The side effects are related directly or indirectly to reduced angiotensin II formation. AKI may occur in conditions where angiotensin plays a crucial role in maintaining GFR such as volume depletion, bilateral renal artery stenosis, polycystic kidney disease, heart failure, and cirrhosis. Diuretic-induced sodium depletion and underlying chronic renal insufficiency are major predisposing factors. Renal insufficiency is usually asymptomatic, nonoliguric, and associated with hyperkalemia. Since angiotensin II levels are rapidly reduced, the rise in the serum creatinine concentration 
generally begins a few days after the institution of therapy. Thus, renal function should be checked at three to five days when an ACE inhibitor is begun in a patient who is at risk for AKI.

AKI occurs in up to $80 \%$ of patients receiving amphotericin B especially when cumulative doses reach 3-4 g. Clinical features are similar to aminoglycosides. In addition, sodium, potassium, and magnesium wasting in the urine may occur. Patient hydration and liposomal forms of the drug have reduced $\mathrm{AKI}{ }^{67}$

The use of the calcineurin inhibitors (CNI), cyclosporine and tacrolimus, has led to major advances in the field of transplantation with excellent short-term outcome. Currently, $94 \%$ of kidney transplant recipients are discharged after transplantation with a CNI-based immunosuppressive regimen. CNIs can result in acute or chronic renal dysfunction. The acute renal dysfunction is due to vasoconstriction due to an imbalance of vasodilator factors like prostacyclin, prostaglandin E2, and nitric oxide and vasoconstrictor factors like endothelin and thromboxane. Acute renal dysfunction due to CNIs is usually reversible with discontinuation or reduction in dose.

\section{Rhabdomyolysis}

Rhabdomyolysis is a syndrome characterized by striated muscle necrosis and the release of intracellular muscle constituent like myoglobin into the circulation. AKI is a potential complication of severe rhabdomyolysis. Patients with acute rhabdomyolysis usually present with pigmented granular casts, reddish-brown urine supernatant, and markedly raised serum creatine kinase. AKI associated with rhabdomyolysis often leads to a more rapid increase in plasma creatinine and lower ratio of BUN to creatinine than do other forms of AKI. Another characteristic feature is the frequent, but not universal, presence of a low $\mathrm{FE}_{\mathrm{Na}}(<1 \%)$, perhaps reflecting the primacy of preglomerular vasoconstriction and tubular occlusion rather than tubular necrosis. ${ }^{68}$

\section{Acute uric acid nephropathy}

Acute uric acid nephropathy causes oliguric or anuric AKI due to intratubular precipitation of uric acid crystals. This is most often due to overproduction and overexcretion of uric acid in patients with lymphoma, leukemia, or a myeloproliferative disease such as polycythemia vera, particularly after chemotherapy or radiation has induced rapid cell lysis. Clinical features are hyperuricemia $(>15 \mathrm{mg} / \mathrm{dL}$ or $893 \mu \mathrm{mol} / \mathrm{L})$, hyperkalemia, hyperphosphatemia, and an increased uric acid-to-creatinine ratio $(>1.0 \mathrm{mg} / \mathrm{mg})$ on a random urine specimen; in comparison, the value is below $0.60-0.75$ in most other forms of AKI ${ }^{69}$ Preventive measures include vigorous hydration and alkaline diuresis. Allopurinol should be started several days before the chemotherapy. The drug, rasburicase, which is the recombinant form of the enzyme uricase that converts uric acid to allantoin, has recently been Food and Drug Administration approved for the prevention and treatment of tumor lysis syndrome.

\section{Acute phosphate nephropathy}

Administration of oral sodium phosphate solution as bowel preparation for colonoscopy has recently been recognized as a cause of AKI. ${ }^{70}$ Risk factors for the development of acute phosphate nephropathy include preexisting chronic kidney disease, inadequate hydration, older age, hypertension treated with ACE inhibitors, ARBs or loop diuretics, female gender, and NSAIDs. Oral phosphate solution is contra-indicated in patients with chronic kidney disease, congestive heart failure, gastrointestinal obstruction, and preexisting electrolyte disorders like hypercalcemia. Recently, five criteria have been proposed to make a diagnosis of acute phosphate nephropathy: ${ }^{70}$ 1) AKI, 2) recent exposure to oral phosphate, 3) renal biopsy findings of acute and chronic tubular injury with abundant calcium phosphate deposits (usually involving more than 40 tubular lumina in a single biopsy), 4) no evidence of hypercalcemia, and 5) no other significant pattern of renal injury on renal biopsy.

\section{Management of AKI}

Successful management of AKI requires early recognition of the diagnosis, investigation of the causes of AKI, management of complications, timely RRT, prevention of ongoing kidney injury, aggressive supportive care, and correction of the primary disorders. Despite many advances in the therapy of AKI, mortality rates remain constant at about $50-80 \%$.

\section{Fluids}

The best way to monitor the adequacy of fluid replacement therapy is a clinical examination of extracellular fluid volume status, urine output, and daily weights. The goal is to achieve and maintain euvolemia while restoring effective circulating volume to allow adequate tissue and kidney perfusion. However, optimal hemodynamic targets for resuscitation are not well defined. Isotonic saline is the appropriate replacement fluid for plasma losses (eg, burns, pancreatitis). The Saline versus Albumin Fluid Evaluation (SAFE) trial compared the use of either $4 \%$ albumin or normal saline for fluid resuscitation in ICU patients. ${ }^{71}$ At 28 days, there was no significant 
difference noted between the two groups with respect to the primary outcome of death or secondary outcomes of organ failure, need for RRT, or duration of hospitalization. Of the patients with severe sepsis, mortality was $30.7 \%$ in those assigned to receive albumin and $35.3 \%$ in patients assigned to receive normal saline $(P=0.09)$. The study also concluded that whether saline or albumin confers benefit in a subgroup of critically ill patients merits further study.

Serum $\mathrm{K}^{+}$and acid-base status should be monitored in all subjects. $\mathrm{K}^{+}$supplementation of replacement fluids should not be given unless there is hypokalemia for example, sodium bicarbonate induced hypokalemia during treatment of metabolic acidosis.

\section{Diuretics}

Diuretics may be useful in volume overload in AKI. Nonoliguric patients with AKI fare better than oliguric patients. ${ }^{72}$ However conversion of oliguria to nonoliguria has not been shown to decrease mortality. Diuretics have not been shown to prevent AKI or improve outcomes in AKI. ${ }^{73}$ In fact, in a multicenter retrospective study of 552 patients with AKI in the ICU, diuretics were used in 326 patients (59\%) at the time of nephrology consultation and with adjustment for relevant covariates and propensity scores, diuretic use was associated with a significant increase in the risk of death or nonrecovery of renal function. ${ }^{74}$

\section{Nutritional support}

Parenteral nutrition compared to other modalities of nutrition in critically ill patients has not been proven to be of benefit. With multiorgan dysfunction uremia is known to accelerate catabolism due to a variety of factors including acidosis, altered counter-regulatory hormonal status, and insulin resistance. A prospective double-blind study randomizing 30 patients with AKI to three isocaloric regimens: glucose alone, glucose plus essential amino acids, or glucose plus essential and non-essential amino acids has been performed. ${ }^{75}$ All patients remained in negative nitrogen balance and remained so throughout the study and no difference in recovery of renal function or survival between treatment groups was noted. In patients on continuous RRT, despite an intake of $2.5 \mathrm{~g} / \mathrm{kg} /$ day of protein, these patients remained in negative nitrogen balance. ${ }^{76}$

In recent reviews of the topic, the following recommendations were made: 1$)$ protein and non protein calories should be provided to meet calculated energy expenditures and at a rate not to exceed $1.5 \mathrm{~g} / \mathrm{kg} /$ day protein intake, 2) nutritional recommendations should not be different from that of critically ill patients as a whole, 3 ) total parentral nutrition should be administered only to patients who are severely malnourished or patients expected to be unable to eat for greater than 14 days, and 4) enteral feeding is the preferred means of nutritional supplementation. ${ }^{77}$

\section{Specific therapies for AKI}

Although the mortality in patients with AKI has declined between 1988 and $2002,{ }^{78}$ the mortality of AKI in the ICU remains high. ${ }^{79}$ Most interventional therapeutic trials in AKI eg, furosemide, ${ }^{80}$ dopamine and furosemide, ${ }^{81}$ anaratide, ${ }^{82,83}$ insulin-like growth factor- $1,{ }^{84}$ and fenoldopam ${ }^{85}$ have failed in humans. A possible reason for the failure of interventional trials in AKI is the dependence on serum creatinine to diagnose AKI. Alterations in serum creatinine may lag 24-48 hours behind actual changes in GFR. ${ }^{7,8}$ Ideally, in the future, early diagnosis of AKI using urine or plasma biomarkers may allow early initiation of specific therapies eg, erythropoietin to treat or prevent worsening of AKI.

\section{Renal replacement therapies}

In the presence of AKI complications such as hypervolemia eg, acute pulmonary edema or large cumulative positive fluid balance, hyperkalemia, metabolic acidosis ( $\mathrm{pH}$ less than 7.1) and uremic symptoms (persistent nausea and vomiting, pericarditis, neuropathy, or an otherwise unexplained decline in mental status) dialysis should be considered as a mainstay therapy. Modalities of RRT include intermittent hemodialysis (IHD), continuous renal replacement therapies (CRRTs), and hybrid therapies, such as sustained low-efficiency dialysis (SLED). Despite these varied techniques, mortality in patients with AKI remains greater than 50\% in severely ill patients. It is possible that variations in the timing of initiation, modalities, and/or dosing of RRT may affect clinical outcomes, particularly survival.

The main considerations when starting a patient with AKI on dialysis are the following: 1) timing of initiation of dialysis, 2 ) the modality of dialysis, and 3) dose of dialysis.

\section{Timing of initiation of dialysis}

Recently, studies have evaluated the relationship between the timing of CRRT initiation and clinical outcomes. In a retrospective study of a single trauma unit, patients were characterized as "early" or "late" starters, based on a BUN of less than or greater than $60 \mathrm{mg} / \mathrm{dL}$, prior to CRRT initiation. Survival was $39 \%$ in early starters compared to $20 \%$ in late starters $(P=0.041) .{ }^{86}$ Two analyses of patients developing AKI following cardiac surgery demonstrated higher survival rates in patients in whom continuous veno-venous 
hemofiltration $(\mathrm{CVVH})$ was initiated in response to a urine output of less than $100 \mathrm{~mL}$ within eight hours consecutively after surgery despite diuretic administration, compared to patients in whom therapy was withheld until objective laboratory criteria using serum creatinine, BUN, and potassium were present. ${ }^{87,88}$ In 243 patients from the Program to Improve Care in Acute Renal Disease (PICARD) study, the risk of death was determined in patients with a BUN of greater than or less than $76 \mathrm{mg} / \mathrm{dL}$ at the initiation of dialysis. After adjustment for age, hepatic failure, sepsis, thrombocytopenia, and serum creatinine and stratified by site and initial dialysis modality, the relative risk for death was 1.85 (95\% confidence interval 1.16-2.96) for the patients with a BUN greater than $76 \mathrm{mg} / \mathrm{dL} .{ }^{89}$ This study provides the rationale for prospective trials of the early initiation of RRT in AKI patients.

\section{Modality of dialysis}

Several retrospective and prospective studies have compared outcomes for continuous versus intermittent modalities. In general, studies are difficult to perform as sicker (eg, severely hypotensive patients are generally started on CVVH) and less sick (eg, mobile, non hypotensive patients are generally started on IHD). In a retrospective study of 349 patients, the mortality rate was higher for continuous versus intermittent dialysis $(68 \%$ versus $41 \%, P<0.001) .{ }^{90}$ However, when multivariate cox analysis was used to adjust for reasons for patient assignment to continuous treatment (eg, systolic blood pressure less than $90 \mathrm{mmHg}$, liver failure etc) there was no increase in risk of death with continuous treatment. In another prospective study, 225 patients in the ICU were divided into three groups: group I (control group): 156 patients with AKI who did not receive dialysis, group II: 21 patients that received IHD or peritoneal dialysis, and group III: 43 patients that received continuous hemodiafiltration. The mortality was higher in patients with renal failure that required dialysis. There was no difference in mortality between patients that required IHD versus CRRT. ${ }^{91}$

A multicenter, randomized, controlled trial was conducted comparing IHD and continuous hemodiafiltration in the ICU. ${ }^{92}$ The 166 patients were randomized. Principal outcome measures were ICU and hospital mortality, length of stay, and recovery of renal function. Despite randomization, there were significant differences between the groups in several covariates independently associated with mortality, including gender, hepatic failure, Acute Physiology and Chronic Health Evaluation II and III scores, and the number of failed organ systems, in each instance biased in favor of the intermittent dialysis group. Using logistic regression to adjust for the imbalances in group assignment, the odds of death associated with continuous therapy was not different compared to IHD. In the most recent study of intermittent versus continuous dialysis in 316 critically ill patients, the modality of RRT had no effect on outcome. ${ }^{93}$ In a metaanalysis of 1,635 patients from nine randomized control trials, it was concluded that CRRT does not confer a survival advantage over IHD. ${ }^{94}$ In conclusion, it is recommended that the modality of dialysis be tailored to the individual patient.

A new hybrid technique is named SLED in which standard IHD equipment is used with reduced dialysate and blood flow rates. In a single center study, 12-hour treatments were performed nocturnally, allowing unrestricted access to the patient for daytime procedures and tests. ${ }^{95}$ The 145 SLED treatments were performed in 37 critically ill patients for whom IHD had failed or been withheld. The study concluded that SLED is a viable alternative to traditional continuous RRTs for critically ill patients in whom IHD has failed due to hypotension or been withheld. ${ }^{95}$

\section{Dose of dialysis}

Three recent single center studies have demonstrated that increased dose of dialysis is associated with a lower mortality. A prospective randomized study of the effect of different ultrafiltration doses in CRRT on survival has recently been performed. ${ }^{96} \mathrm{~A}$ total of 425 patients in ICU, with a mean age of 61 years, who had AKI were studied. Patients were randomly assigned ultrafiltration at $20 \mathrm{~mL} / \mathrm{hr} / \mathrm{kg}$ (group 1, $\mathrm{n}=146$ ), $35 \mathrm{~mL} /$ $\mathrm{hr} / \mathrm{kg}$ (group 2, $\mathrm{n}=139$ ), or $45 \mathrm{~mL} / \mathrm{hr} / \mathrm{kg}$ (group 3, $\mathrm{n}=140$ ). The primary endpoint was survival at 15 days after stopping hemofiltration. Survivors in all groups had lower concentrations of BUN before continuous hemofiltration was started than nonsurvivors. The frequency of complications was similarly low in all groups. Mortality among these critically ill patients was high, but patients receiving the higher dose of ultrafiltration (groups 2 and 3) had significantly improved survival. In another study, 160 patients with ARF were assigned to receive daily or alternate day IHD. The mortality rate, according to the intention-to-treat analysis, was $28 \%$ for daily dialysis and $46 \%$ for alternate-day dialysis $(P=0.01) \cdot{ }^{97}$ The hypothesis that an increase in dialysis dose obtained by using continuous veno-venous hemodiafiltration (CVVHDF) is associated with a better survival than CVVH was tested in 206 patients. ${ }^{98}$ Twenty eight day and three month survival was significantly higher in the CVVHDF group that received an increased dose of dialysis. In view of the promising single center studies, a large multicenter study, the ATN study, was performed by the Veteran's Administration/National Institues of Health ARF Trial network..$^{99}$ In 1,124 critically ill patients with $\mathrm{AKI}$, intensive renal support did not decrease 
Table 7 Dose of dialysis in AKI

\begin{tabular}{|c|c|c|c|}
\hline No of patients & Study design & Results & Ref \\
\hline 425 patients; single center & Dose of CVVH & $\begin{array}{l}\text { Ultrafiltration at } 35 \text { or } 45 \mathrm{~mL} / \text { hour } / \mathrm{kg} \\
\text { better patient survival than } \\
20 \mathrm{~mL} / \text { hour } / \mathrm{kg}\end{array}$ & 96 \\
\hline I60 patients; single center & Daily or alternate day hemodialysis & $\begin{array}{l}\text { Daily hemodialysis better patient } \\
\text { survival than alternate day } \\
\text { hemodialysis }\end{array}$ & 97 \\
\hline 206 patients; single center & $\begin{array}{l}\text { Increase in dialysis dose by adding } \\
\text { CVVHDF to CVVH }\end{array}$ & $\begin{array}{l}\text { CVVH }+ \text { CVVHDF better patient } \\
\text { survival than CVVH alone }\end{array}$ & 98 \\
\hline $\begin{array}{l}\text { ATN study; I, I } 24 \text { patients } \\
\text { multicenter }\end{array}$ & $\begin{array}{l}\text { 3/week HD (Kt/V > } 1.2 \text { per HD) or } \\
\mathrm{CVVH} 20 \mathrm{~mL} / \mathrm{hour} / \mathrm{kg} \text { versus 6/week } \\
\mathrm{HD} \text { or } \mathrm{CVVH} 35 \mathrm{~mL} / \text { hour } / \mathrm{kg}\end{array}$ & $\begin{array}{l}\text { Patient survival was the same intensive } \\
\text { versus conventional dialysis }\end{array}$ & 99 \\
\hline $\begin{array}{l}\text { RENAL study; I,508 } \\
\text { patients }\end{array}$ & $\begin{array}{l}\mathrm{CVVH} \text { at } 25 \mathrm{~mL} / \mathrm{hour} / \mathrm{kg} \text { versus } \\
40 \mathrm{~mL} / \mathrm{hour} / \mathrm{kg}\end{array}$ & $\begin{array}{l}\text { Mortality at } 90 \text { days the same in } \\
\text { intensive versus conventional dose } \\
\text { of } \mathrm{CVVH}\end{array}$ & 100 \\
\hline
\end{tabular}

mortality, improve recovery of kidney function, or reduce the rate of nonrenal organ failure as compared with less-intensive therapy. The RENAL (Randomised Evaluation of Normal versus Augmented Level of Replacement Therapy) is the largest interventional trial in AKI patients. The 1,502 patients were randomized to receive CVVH with effluent flow of $40 \mathrm{~mL} / \mathrm{hour} / \mathrm{kg}$ (high intensity) or $25 \mathrm{~mL} /$ hour/ $\mathrm{kg}$ (low intensity). ${ }^{100}$ At 90 days after randomization, the mortality was the same in both groups $-44.7 \%$ at 90 days. There were $6.8 \%$ of the survivors of the high intensity group compared to $4.5 \%$ of the survivors of the low intensity group still on CVVH at 90 days $(P=0.14)$. In an editorial on the ATN and RENAL studies, ${ }^{101}$ it was concluded that 1) the failure to demonstrate improved outcomes with more intensive RRT does not imply that the intensity of RRT does not matter, ${ }^{101}$ 2) a minimal dosing threshold must be achieved to obtain optimal clinical outcomes (eg, in the ATN study, each $\mathrm{HD}$ was dosed to have a Kt/V of $>1.2$. In the RENAL study, CVVH was dosed per body weight and blood flow was kept above $150 \mathrm{~mL} / \mathrm{min}$ ), and 3) in practice, dialysis should be dosed for the individual patient. The studies examining the dose of dialysis in AKI are listed in Table 7.

\section{Acknowledgment}

This work was supported by NIH grants RO1-DK-056851 and RO1-DK-074835 (To CLE).

\section{Disclosure}

The authors report no conflicts of interest.

\section{References}

1. Lassnigg A, Schmidlin D, Mouhieddine M, et al. Minimal changes of serum creatinine predict prognosis in patients after cardiothoracic surgery: a prospective cohort study. J Am Soc Nephrol. 2004;15(6):1597-1605.

2. Van Biesen W, Vanholder R, Lameire N. Defining acute renal failure: RIFLE and beyond. Clin J Am Soc Nephrol. 2006;1(6):1314-1319.
3. Bellomo R, Kellum JA, Ronco C. Defining and classifying acute renal failure: from advocacy to consensus and validation of the RIFLE criteria. Intensive Care Med. 2007;33(3):409-413.

4. Waikar SS, Liu KD, Chertow GM. Diagnosis, epidemiology, and outcomes of acute renal failure. Clin J Am Soc Nephrol. 2008;3(3): 844-861.

5. Haase M, Bellomo R, Matalanis G, Calzavacca P, Dragun D, Haase-Fielitz A. A comparison of the RIFLE and Acute Kidney Injury Network classifications for cardiac surgery-associated acute kidney injury: a prospective cohort study. J Thorac Cardiovasc Surg. 2009; 138(6):1370-1376

6. Stevens LA, Lafayette RA, Perrone RD, Levey AS. Laboratory evaluation of kidney function. In: Scrier RW. Diseases of the Kidney and Urinary Tract. 8th ed. Philadelphia: Lippincott Williams \& Wilkins; 2007.

7. Moran SM, Myers BD. Course of acute renal failure studied by a model of creatinine kinetics. Kidney Int. 1985;27(6):928-937.

8. Star RA. Treatment of acute renal failure. Kidney Int. 1998;54(6): $1817-1831$

9. Chronopoulos A, Cruz DN, Ronco C. Hospital-acquired acute kidney injury in the elderly. Nat Rev Nephrol. 2010;6(3):141-149.

10. Melnikov VY, Ecder T, Fantuzzi G, et al. Impaired IL-18 processing protects caspase-1-deficient mice from ischemic acute renal failure. $J$ Clin Invest. 2001;107(9):1145-1152.

11. Melnikov VY, Faubel SG, Siegmund B, Lucia MS, Ljubanovic D, Edelstein CL. Neutrophil-independent mechanisms of caspase-1- and IL-18-mediated ischemic acute tubular necrosis in mice. J Clin Invest. 2002;110(8):1083-1091.

12. Parikh CR, Jani A, Mishra J, et al. Urine NGAL and IL-18 are predictive biomarkers for delayed graft function following kidney transplantation. Am J Transplant. 2006;6(7):1639-1645.

13. Parikh CR, Jani A, Melnikov VY, Faubel SG, Edelstein CL. Urinary interleukin-18 is a marker of human acute tubular necrosis. Am J Kidney Dis. 2004;43:405-414.

14. Parikh CR, Abraham E, Ancukiewicz M, Edelstein CL. Urine IL-18 is an early diagnostic marker for acute kidney injury and predicts mortality in the ICU. J Am Soc Nephrol. 2005;16:3046-3052.

15. Washburn KK, Zapitelli M, Arikan AA, et al. Urinary interleukin-18 as an acute kidney injury biomarker in critically ill children. Nephrol Dial Transplant. 2008;23(2):566-572.

16. Parikh CR, Mishra J, Thiessen-Philbrook H, Dursun B, et al. Urinary IL-18 is an early predictive biomarker of acute kidney injury after cardiac surgery. Kidney Int. 2006;70(1):199-203.

17. Ling $\mathrm{W}$, Zhaohui N, Ben H, et al. Urinary IL-18 and NGAL as early predictive biomarkers in contrast-induced nephropathy after coronary angiography. Nephron Clin Pract. 2008;108(3):176-181. 
18. Schmidt-Ott KM, Mori K, Li JY, et al. Dual action of neutrophil gelatinase-associated lipocalin. J Am Soc Nephrol. 2007;18(2): 407-413.

19. Mishra J, Ma Q, Prada A, et al. Identification of neutrophil gelatinaseassociated lipocalin as a novel early urinary biomarker for ischemic renal injury. J Am Soc Nephrol. 2003;14(10):2534-2543.

20. Mishra J, Mori K, Ma Q, Kelly C, Barasch J, Devarajan P. Neutrophil gelatinase-associated lipocalin: a novel early urinary biomarker for cisplatin nephrotoxicity. Am J Nephrol. 2004;24(3):307-315.

21. Mishra J, Dent C, Tarabishi R, et al. Neutrophil gelatinase-associated lipocalin (NGAL) as a biomarker for acute renal injury after cardiac surgery. Lancet. 2005;365(9466):1231-1238.

22. Wagener G, Jan M, Kim M, et al. Association between increases in urinary neutrophil gelatinase-associated lipocalin and acute renal dysfunction after adult cardiac surgery. Anesthesiology. 2006;105(3): 485-491.

23. Zapitelli M, Washburn KK, Arikan AA, et al. Urine neutrophil gelatinase-associated lipocalin is an early marker of acute kidney injury in critically ill children: a prospective cohort study. Crit Care. 2007;11(4):R84.

24. Wheeler DS, Devarajan P, Ma Q, et al. Serum neutrophil gelatinaseassociated lipocalin (NGAL) as a marker of acute kidney injury in critically ill children with septic shock. Crit Care Med. 2008;36(4): 1297-1303.

25. Hirsch R, Dent C, Pfriem H, et al. NGAL is an early predictive biomarker of contrast-induced nephropathy in children. Pediatr Nephrol. 2007;22(12):2089-2095.

26. Bachorzewska-Gajewska H, Malyszko J, Sitniewska E, Malyszko JS, Dobrzycki S. Neutrophil-gelatinase-associated lipocalin and renal function after percutaneous coronary interventions. Am J Nephrol. 2006;26(3):287-292.

27. Siew ED, Ware LB, Gebretsadik T, et al. Urine neutrophil gelatinaseassociated lipocalin moderately predicts acute kidney injury in critically ill adults. J Am Soc Nephrol. 2009;20(8):1823-1832.

28. Cruz DN, de Cal M, Garzotto F, et al. Plasma neutrophil gelatinaseassociated lipocalin is an early biomarker for acute kidney injury in an adult ICU population. Intensive Care Med. 2010;36(3):444-451.

29. Niemann CU, Walia A, Waldman J, et al. Acute kidney injury during liver transplantation as determined by neutrophil gelatinase-associated lipocalin. Liver Transpl. 2009;15(12):1852-1860.

30. Haase M, Bellomo R, Devarajan P, Schlattmann P, Haase-Fielitz A; NGAL Meta-analysis Investigator Group. Accuracy of neutrophil gelatinase-associated lipocalin (NGAL) in diagnosis and prognosis in acute kidney injury: a systematic review and meta-analysis. Am J Kidney Dis. 2009;54(6):1012-1024.

31. Ichimura T, Bonventre JV, Bailly V, et al. Kidney injury molecule-1 (KIM-1), a putative epithelial cell adhesion molecule containing a novel immunoglobulin domain, is up-regulated in renal cells after injury. $J$ Biol Chem. 1998;273(7):4135-4142.

32. Vaidya VS, Ramirez V, Ichimura T, Bobadilla NA, Bonventre JV. Urinary kidney injury molecule-1: a sensitive quantitative biomarker for early detection of kidney tubular injury. Am J Physiol Renal Physiol. 2006;290(2):F517-F529.

33. Han WK, Bailly V, Abichandani R, Thadhani R, Bonventre JV. Kidney injury molecule-1 (KIM-1): a novel biomarker for human renal proximal tubule injury. Kidney Int. 2002;62(1):237-244.

34. Van Timmeren MM, Vaidya VS, van Ree RM, et al. High urinary excretion of kidney injury molecule-1 is an independent predictor of graft loss in renal transplant recipients. Transplantation. 2007; 84(12): 1625-1630.

35. Vaidya VS, Ford GM, Waikar SS, et al. A rapid urine test for early detection of kidney injury. Kidney Int. 2009;76(1):108-114.

36. Han WK, Wagener G, Zhu Y, Wang S, Lee HT. Urinary biomarkers in the early detection of acute kidney injury after cardiac surgery. Clin J Am Soc Nephrol. 2009;4(5):873-882.

37. Westhuyzen J. Cystatin C. A promising marker and predictor of impaired renal function. Ann Clin Lab Sci. 2006;36(4):387-394.
38. Herget-Rosenthal S, Marggraf G, Husing J, et al. Early detection of acute renal failure by serum cystatin C. Kidney Int. 2004;66(3):1115-1122.

39. Koyner JL, Bennet MR, Worcester EM, et al. Urinary cystatin C as an early biomarker of acute kidney injury following adult cardiothoracic surgery. Kidney Int. 2008;74(8):1059-1069.

40. Artunc FH, Fischer IU, Risler T, Erley CM. Improved estimation of GFR by serum cystatin $\mathrm{C}$ in patients undergoing cardiac catheterization. Int J Cardiol. 2005;102(2):173-178.

41. Orlando R, Mussap M, Plebani M, et al. Diagnostic value of plasma cystatin $\mathrm{C}$ as a glomerular filtration marker in decompensated liver cirrhosis. Clin Chem. 2002;48(6 Pt 1):850-858.

42. Gerbes AL, Gulberg V, Bilzer M, Vogeser M. Evaluation of serum cystatin $\mathrm{C}$ concentration as a marker of renal function in patients with cirrhosis of the liver. Gut. 2002;50(1):106-110.

43. Villa P, Jimenez M, Soriano MC, Manzanares J, Casasnovas P. Serum cystatin $\mathrm{C}$ concentration as a marker of acute renal dysfunction in critically ill patients. Crit Care. 2005;9(2):R139-R143.

44. Herrero-Morin JD, Malaga S, Fernandez N, et al. Cystatin C and beta2microglobulin: markers of glomerular filtration in critically ill children. Crit Care. 2007;11(3):R59.

45. Perianayagam MC, Seabra VF, Tighiouart H, Liangos O, Jaber BL. Serum cystatin $\mathrm{C}$ for prediction of dialysis requirement or death in acute kidney injury: a comparative study. Am J Kidney Dis. 2009;54(6):1025-1033.

46. Kanbay M, Kesapoglu B, Perazella MA. Acute tubular necrosis and prerenal acute kidney injury: utility of urine microscopy in their evaluation-a systematic review. Int Urol Nephrol. 2009; Nov 17. [Epub ahead of print]

47. Perazella MA, Coca SG, Hall IE, Iyanam U, Koraishy M, Parikh CR Urine microscopy is associated with severity and worsening of acute kidney injury in hospitalized patients. Clin J Am Soc Nephrol. 2010; 5(3):402-408.

48. Miller TR, Anderson RJ, Linas SL, et al. Urinary diagnostic indices in acute renal failure: a prospective study. Ann Intern Med. 1978;89(1): 47-50.

49. Handa SP, Morrin PA. Diagnostic indices in acute renal failure. Can Med Assoc J. 1967;96(2):78-82.

50. Vertel RM, Knochel JP. Nonoliguric acute renal failure. JAMA. 1967; 200(7):598-602.

51. Brivet FG, Kleinknecht DJ, Loirat P, Landais PJ. Acute renal failure in intensive care units -causes, outcome, and prognostic factors of hospital mortality: a prospective, multicenter study. Crit Care Med. 1996;24(2): 192-198.

52. Liano F, Junco E, Pascual J, Madero R, Verde E. The spectrum of acute renal failure in the intensive care unit compared with that seen in other settings. Kidney Int Suppl. 1998;66:S16-S24.

53. Schrier RW, Wang W. Acute renal failure and sepsis. $N$ Engl J Med. 2004;351(2):159-169.

54. Sheikh-Hamad D, Timmins K, Jalali Z. Cisplatin-induced renal toxicity: possible reversal by $\mathrm{N}$-acetylcysteine treatment. J Am Soc Nephrol. 1997;8(10):1640-1644.

55. Dentino M, Luft FC, Yum MN, Williams SD, Einhorn LH. Long term effect of cis-diamminedichloride platinum (CDDP) on renal function and structure in man. Cancer. 1978;41(4):1274-1281.

56. Kanbay M, Covic A, Coca SG, Turgut F, Akcay A, Parikh CR. Sodium bicarbonate for the prevention of contrast-induced nephropathy: a meta-analysis of 17 randomized trials. Int Urol Nephrol. 2009;41(3):617-627.

57. Heyman SN, Reichman J, Brezis M. Pathophysiology of radiocontrast nephropathy: a role for medullary hypoxia. Invest Radiol. 1999;34(11):685-691.

58. Kohan DE. Endothelins in the normal and diseased kidney. Am J Kidney Dis. 1997;29(1):2-26.

59. Solomon R. Radiocontrast-induced nephropathy. Semin Nephrol. 1998; 18(5):551-557.

60. Rudnick MR, Berns JS, Cohen RM, Goldfarb S. Nephrotoxic risks of renal angiography: contrast media-associated nephrotoxicity and atheroembolism - a critical review. Am J Kidney Dis. 1994;24(4):713-727. 
61. Tepel M, van der GM, Schwarzfeld C, Laufer U, Liermann D, Zidek W. Prevention of radiographic-contrast-agent-induced reductions in renal function by acetylcysteine. $N$ Engl J Med. 2000;343(3):180-184.

62. Riley DJ, Weir M, Bakris GL. Renal adaptation to the failing heart. Avoiding a 'therapeutic misadventure'. Postgrad Med. 1994;95(8):153-156.

63. Tan SY, Shapiro R, Kish MA. Reversible acute renal failure induced by indomethacin. JAMA. 1979;241(25):2732-2733.

64. Galler M, Folkert VW, Schlondorff D. Reversible acute renal insufficiency and hyperkalemia following indomethacin therapy. JAMA. 1981;246(2):154-155.

65. Baldwin DS, Levine BB, McCluskey RT, Gallo GR. Renal failure and interstitial nephritis due to penicillin and methicillin. $N$ Engl $J$ Med. 1968;279(23): 1245-1252.

66. Rossert J. Drug-induced acute interstitial nephritis. Kidney Int. 2001; 60(2):804-817.

67. Taber SS, Pasko DA. The epidemiology of drug-induced disorders: the kidney. Expert Opin Drug Saf. 2008;7(6):679-690.

68. Corwin HL, Schreiber MJ, Fang LS. Low fractional excretion of sodium. Occurrence with hemoglobinuric- and myoglobinuric-induced acute renal failure. Arch Int Med. 1984;144(5):981-982.

69. Kelton J, Kelley WN, Holmes EW. A rapid method for the diagnosis of acute uric acid nephropathy. Arch Intern Med.1978;138(4):612-615.

70. Markowitz GS. Oral sodium phosphate bowel purgatives and acute phosphate nephropathy. In: De Broe ME, Porter GA. Clinical NephrotoxinsRenal Injury from Drugs and Chemicals. 3rd ed. New York: Springer; 2008.

71. Finfer S, Bellomo R, Boyce N, Myburgh J, Norton R; SAFE Study Investigators. A comparison of albumin and saline for fluid resuscitation in the intensive care unit. $N$ Engl J Med. 2004;350(22):2247-2256.

72. Anderson RJ, Linas SL, Berns AS, et al. Nonoliguric acute renal failure. N Engl J Med. 1977;296:1134-1138.

73. Karajala V, Mansour W, Kellum JA. Diuretics in acute kidney injury. Minerva Anestesiol. 2009;75(5):251-257.

74. Mehta RL, Pascual MT, Soroko S, Chertow GM; PICARD Study Group. Diuretics, mortality, and nonrecovery of renal function in acute renal failure. JAMA. 2002;288(20):2547-2553.

75. Feinstein EI, Kopple JD, Silberman H, Massry SG. Total parenteral nutrition with high or low nitrogen intakes in patients with acute renal failure. Kidney Int Suppl. 1983;16:S319-S323.

76. Bellomo R, Seacombe J, Daskalakis M, et al. A prospective comparative study of moderate versus high protein intake for critically ill patients with acute renal failure. Ren Fail. 1997;19(1):111-120.

77. Sponsel $\mathrm{H}$, Conger JD. Is parenteral nutrition therapy of value in acute renal failure patients? Am J Kidney Dis. 1995;25(1):96-102.

78. Waikar SS, Curhan GC, Wald R, McCarthy EP, Chertow GM. Declining mortality in patients with acute renal failure, 1988 to 2002. J Am Soc Nephrol. 2006;17(4):1143-1150.

79. Lameire N, Van Biesen W, Vanholder R. The changing epidemiology of acute renal failure. Nat Clin Pract Nephrol. 2006;2(7):364-377.

80. Shilliday IR, Quinn KJ, Allison ME. Loop diuretics in the management of acute renal failure: a prospective, double-blind, placebo-controlled, randomized study. Nephrol Dial Transplant. 1997;12(12):2592-2596.

81. Lassnigg A, Donner E, Grubhofer G, Presterl E, Druml W, Hiesmayr M. Lack of renoprotective effects of dopamine and furosemide during cardiac surgery. J Am Soc Nephrol. 2000;11(1):97-104.

82. Allgren RL, Marbury TC, Rahman SN, et al. Anaritide in acute tubular necrosis. N Engl J Med. 1997;336(12):828-834.
83. Lewis J, Salem MM, Chertow GM, et al. Atrial natriuretic factor in oliguric acute renal failure. Anaritide Acute Renal Failure Study Group. Am J Kidney Dis. 2000;36(4):767-774.

84. Hirschberg R, Kopple J, Lipsett P, et al. Multicenter clinical trial of recombinant human insulin-like growth factor I in patients with acute renal failure. Kidney Int. 1999;55(6):2423-2432.

85. Kellum JA. Prophylactic fenoldopam for renal protection? No, thank you, not for me - not yet at least. Critical Care Med. 2005;33(11): 2681-2683.

86. Gettings LG, Reynolds HN, Scalea T. Outcome in post-traumatic acute renal failure when continuous renal replacement therapy is applied early vs late. Intensive Care Med. 1999;25(8):805-813.

87. Elahi MM, Lim MY, Joseph RN, Dhannapuneni RR, Spyt TJ. Early hemofiltration improves survival in post-cardiotomy patients with acute renal failure. Eur J Cardiothorac Surg. 2004;26(5):1027-1031.

88. Demirkilic U, Kuralay E, Yenicesu M, et al. Timing of replacement therapy for acute renal failure after cardiac surgery. J Card Surg. 2004; 19(1):17-20.

89. Liu KD, Himmelfarb J, Paganini E, et al. Timing of initiation of dialysis in critically ill patients with acute kidney injury. Clin J Am Soc Nephrol. 2006;1(5):915-919.

90. Swartz RD, Messana JM, Orzol S, Port FK. Comparing continuous hemofiltration with hemodialysis in patients with severe acute renal failure. Am J Kidney Dis. 1999;34(3):424-432.

91. Rialp G, Roglan A, Betbese AJ, et al. Prognostic indexes and mortality in critically ill patients with acute renal failure treated with different dialytic techniques. Ren Fail. 1996;18(4):667-675.

92. Mehta RL, McDonald B, Gabbai FB, et al. A randomized clinical trial of continuous versus intermittent dialysis for acute renal failure. Kidney Int. 2001;60(3):1154-1163.

93. Lins RL, Elseviers MM, van der Neipen P, et al. Intermittent versus continuous renal replacement therapy for acute kidney injury patients admitted to the intensive care unit: results of a randomized clinical trial. Nephrol Dial Transplant. 2009;24(2):512-518.

94. Ghahramani N, Shadrou S, Hollenbeak C. A systematic review of continuous renal replacement therapy and intermittent hemodialysis in management of patients with acute renal failure. Nephrology. 2008; 13(7):570-578.

95. Marshall MR, Golper TA, Shaver MJ, Alam MG, Chatoth DK. Sustained low-efficiency dialysis for critically ill patients requiring renal replacement therapy. Kidney Int. 2001;60(2):777-785.

96. Ronco C, Bellomo R, Homel P, et al. Effects of different doses in continuous veno-venous hemofiltration on outcomes of acute renal failure: a prospective randomized trial. Lancet. 2000;356(9223):26-30.

97. Schiffl H, Lang SM, Fischer R. Daily hemodialysis and the outcome of acute renal failure. $N$ Engl J Med. 2002;346(5):305-310.

98. Saudan P, Niederberger M, De Seigneux S, et al. Adding a dialysis dose to continuous hemofiltration increases survival in patients with acute renal failure. Kidney Int. 2006;70(7):1312-1317.

99. VA/NIH Acute Renal Failure Trial Network; Palevsky PM, Zhang JH, et al. Intensity of renal support in critically ill patients with acute kidney injury. N Engl J Med. 2008;359(1):7-20.

100. RENAL Replacement Therapy Study Investigators; Bellomo R, Cass A, et al. Intensity of continuos renal-replacement therapy in critically ill patients. $N$ Engl J Med. 2009;361(17):1627-1638.

101. Palevsky PM. Renal support in acute kidney injury - how much is enough? N Engl J Med. 2009;361(17):1699-1701.

International Journal of Nephrology and Renovascular Disease

\section{Publish your work in this journal}

The International Journal of Nephrology and Renovascular Disease is an international, peer-reviewed open-access journal focusing on the pathophysiology of the kidney and vascular supply. Epidemiology, screening, diagnosis, and treatment interventions are covered as well as basic science, biochemical and immunological studies. The journal welcomes

\section{Dovepress}

original research, clinical studies, reviews \& evaluations, expert opinion and commentary, case reports and extended reports. The manuscript management system is completely online and includes a very quick and fair peerreview system, which is all easy to use. Visit http://www.dovepress.com/ testimonials.php to read real quotes from published authors. 